\title{
SÍNTESE DE BIODIESEL UTILIZANDO ARGILA BENTONÍTICA NATURAL E IMPREGNADA COMO CATALISADOR
}

\author{
J. C. MARINHO ${ }^{1}$, P. H. D. FELIX ${ }^{1}$, E. G. LIMA, M. W. N. C. CARVALHO e A. A. CUTRIM \\ ${ }^{1}$ Universidade Federal de Campina Grande, Departamento de Engenharia Química \\ E-mail para contato: Janaina.esa@gmail.com
}

\begin{abstract}
RESUMO - As argilas são materiais usados em diversas aplicações industriais e que atualmente apresentam inúmeros estudos devido às interessantes propriedades que apresentam. Podendo ser utilizado como adsorventes ou catalisadores em reações químicas, passando por tratamentos químicos, pois a argila na forma natural não possui atividade catalítica, podendo ser destacado o processo de impregnação. Nesta perspectiva, surgem propostas para as rotas de síntese de biodiesel que se valem da catalise heterogênea utilizando argila como uma metodologia promissora. Nesse trabalho tivemos como objetivo analisar os resultados obtidos das caracterizações da argila bentonítica na forma natural e impregnada e do biodiesel sintetizado. Entretanto, para a argila impregnada, foi realizado um processo de dispersão física. As argilas foram caracterizadas por DRX, MEV e EDS. Os biodieseis sintetizados foram analisados através da viscosidade cinemática e cromatografia gasosa da conversão o óleo de soja em éster etílico. Os resultados demonstraram a potencialidade da atividade catalítica da argila bentonítica impregnada para conversão de ésteres.
\end{abstract}

Palavras-chaves: Argila, Catalisador, Biodiesel.

\section{INTRODUÇÃO}

Diversas oleaginosas podem ser utilizadas como matéria prima na síntese do biodiesel, entre elas destaca-se o óleo de soja. A utilização deste óleo é interessante, pois a soja possui produção em grande escala (1).

A obtenção do biodiesel através da síntese por rota heterogênea é alvo de diversas pesquisas por este superar gargalos apresentados na síntese utilizada pela rota homogênea (2). Dentre os principais inconvenientes apresentados na síntese convencional (transesterificação homogênea com catálise básica) encontra-se a etapa de separação e purificação do combustível, que é demorada e gera uma grande quantidade de resíduos. Entre os materiais que podem atuar como catalisadores heterogêneos estão às argilas, que apresentam como principal vantagem ser um material de baixo custo, encontrado com abundância na natureza e que possui propriedades catalíticas (3).

As argilas despertam grande interesse para a indústria, pois apresentam na sua estrutura características favoráveis em suas aplicações. No entanto, as modificações químicas dessas estruturas são também possíveis, podendo ser aplicadas como catalisadores (4). As argilas podem ser 
quimicamente tratadas podendo ser destacado o processo de impregnação. A impregnação consiste na inserção do metal na estrutura dos suportes catalíticos potencializando a fase ativa para que possam ser aplicados como catalisadores de forma mais eficiente (5). $\mathrm{O}$ óxido de molibdênio tem sido utilizado como fase ativa na obtenção do biodiesel por apresentar os sítios ácidos de Lewis e de Brönsted (1).

O presente trabalho tem como objetivo estudar o uso e o desempenho da argila bentonítica na forma natural e impregnada com óxido de molibdênio como catalisador na reação de transesterificação utilizando óleo de soja.

\section{METODOLOGIA}

\section{Seleção da Argila}

A argila bentonítica importada sódica, denominada de Bentogel - J, utilizada foi fornecida pela empresa BENTONISA - BENTONITA DO NORDESTE S. A. A argila Bentogel - J foi submetida ao processo de impregnação.

\section{Impregnação}

A argila natural foi impregnada com $7,5 \%$ do óxido de molibdênio, utilizando para essa impregnação o molibdato de amônio e com o auxílio do almofariz e pistilo foi misturada a argila natural com o sal de molibdato por 30 minutos. Em seguida, este material foi seco a temperatura de $60{ }^{\circ} \mathrm{C}$ durante 24 horas e calcinado a $550{ }^{\circ} \mathrm{C}$ durante 4 horas (1). Os materiais argilosos na forma natural e impregnada foram caracterizados por Difração de Raios X (DRX), Microscopia Eletrônica de Varredura (MEV) e Espectroscopia de Energia Dispersiva (EDS).

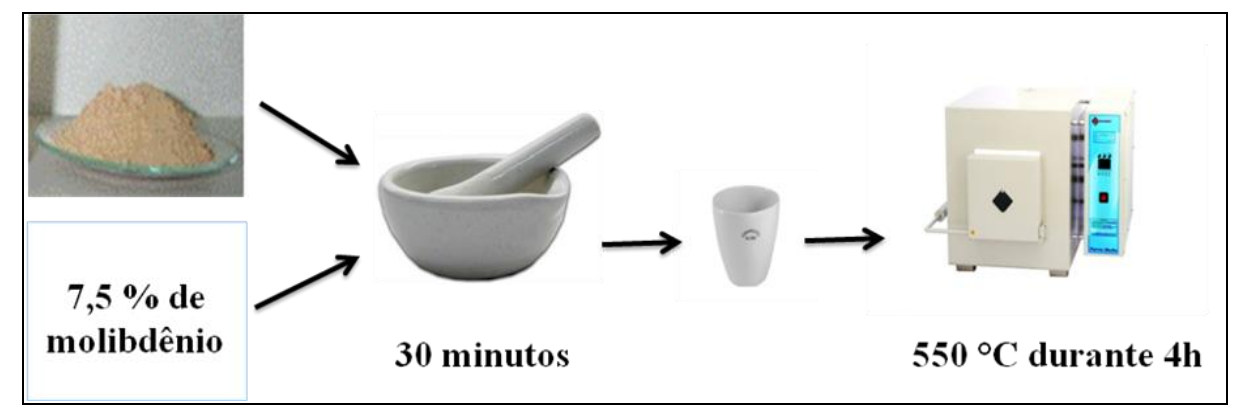

Figura 1: Processo de Impregnação.

\section{Síntese de biodiesel}

Na metodologia para obtenção do biodiesel utilizou-se óleo de soja e álcool etílico P.A. (1:12) e catalisador (argila) (2). Nesta síntese de biodiesel foi utilizado como catalisador a argila Bentonítica 
Natural e a argila Bentonítica Impregnada. A reação ocorreu em um sistema denominado reator batelada com pressão autógena. Utilizou-se uma estufa para aquecimento do reator, a reação ocorreu sob uma temperatura de $200^{\circ} \mathrm{C}$ com duração de 4 horas (Figura 2). No fim da reação, o biodiesel obtido foi lavado com água a uma temperatura de $40{ }^{\circ} \mathrm{C}$ até eliminar toda a glicerina formada na reação, em seguida, foi seco na estufa durante $1 \mathrm{~h}$ a $90^{\circ} \mathrm{C}$, sendo então caracterizado por medidas de viscosidade cinemática e por cromatografia gasosa.

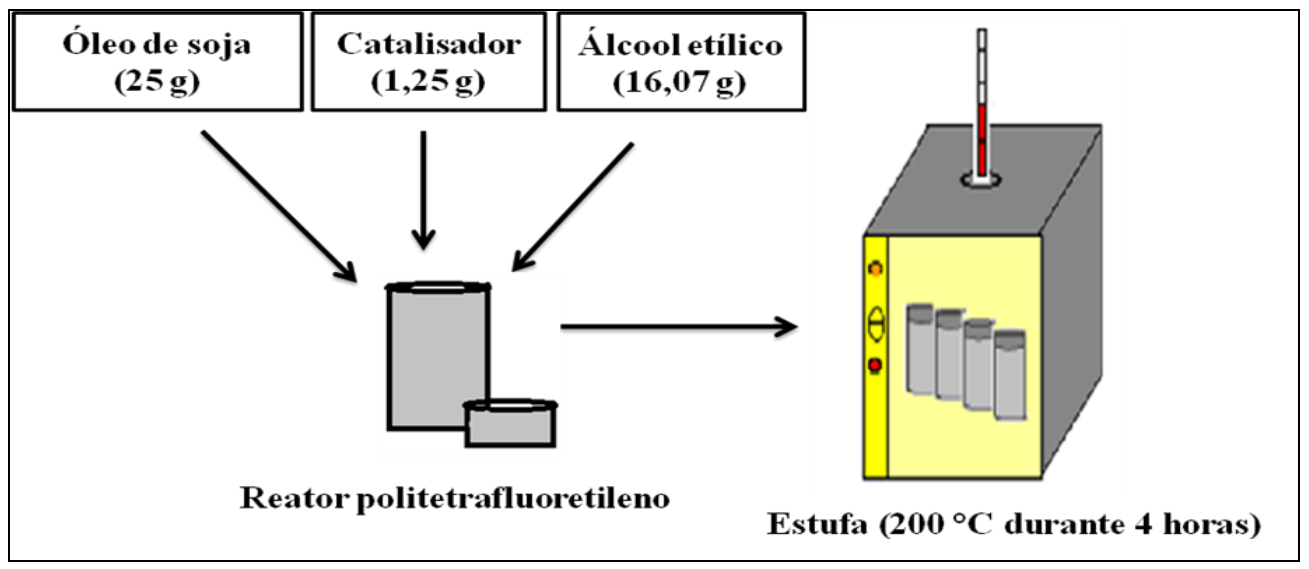

Figura 2: Síntese do biodiesel.

\section{RESULTADOS E DISCUSSÃO}

\section{Difração de Raios X}

Os resultados de difração de raios $\mathbf{X}$ para as argilas Bentogel - $\mathbf{J}$ natural e Bentogel $-\mathbf{J}$ impregnada podem ser observados através das Figuras 3 e 4, respectivamente.

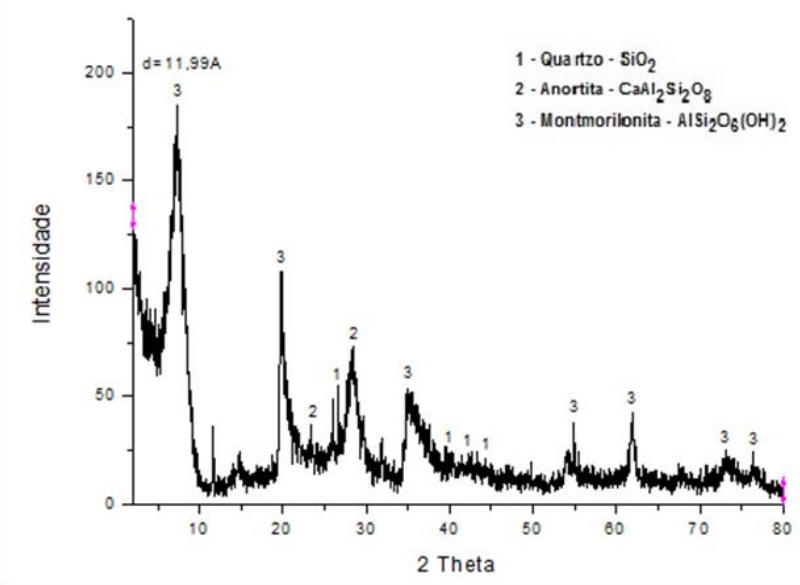

Figura 3: Difratograma de raios $X$ da argila Bentogel - J natural.

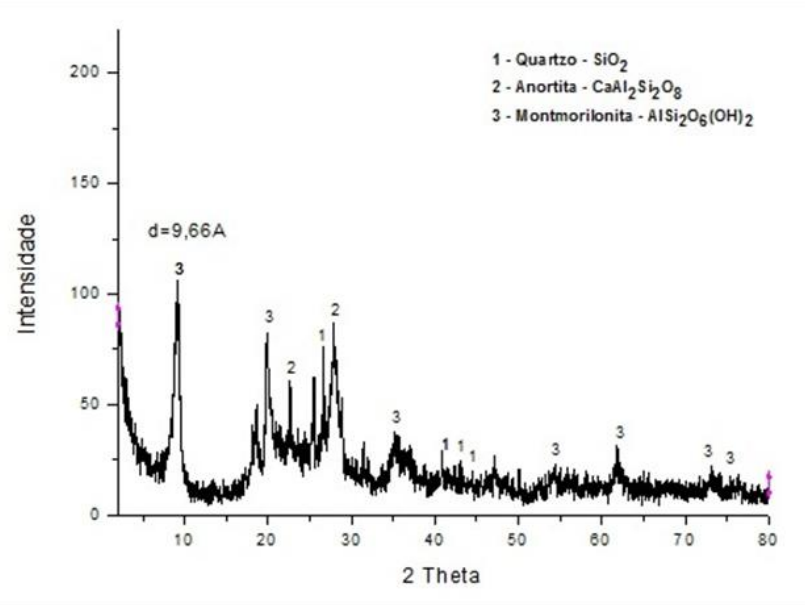

Figura 4: Difratograma de raios $X$ da argila Bentogel - J impregnada. 
Analisando os difratogramas de raios $\mathrm{X}$ da argila Bentongel - $\mathrm{J}$ natural (Figura 3) foi possível verificar a presença de três fases na estrutura, a fase quartzo ( $\mathrm{SiO} 2)$, anortita $\left(\mathrm{CaAl}_{2} \mathrm{Si}_{2} \mathrm{O}_{8}\right)$ e montmorilonita $\left(\mathrm{AlSi}_{2} \mathrm{O}_{6}(\mathrm{OH})_{2}\right)$. Observa-se também que a fase predominante é a da montmorilonita (do grupo esmectita), caracterizando ser uma argila bentonítica.

Comparando os difratogramas de difração de raios $\mathrm{X}$ da argila Bentogel - J impregnada (Figura 4) com a argila Bentogel - J natural (Figura 3) pode-se observar que houve uma redução do

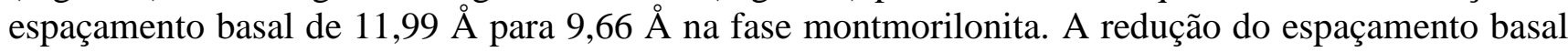
da argila Bentogel - J impregnada deve-se ao processo do tratamento térmico (calcinação) que esta amostra foi submetida, promovida pelo processo de impregnação.

\section{$\underline{\text { Microscopia Eletrônica de Varredura (MEV) }}$}

Os resultados obtidos através da Microscopia Eletrônica de Varredura para as argilas Bentogel - J natural e Bentogel - J impregnada podem ser observados através da Figura 5 e 6, respectivamente, com ampliação de 5000x.

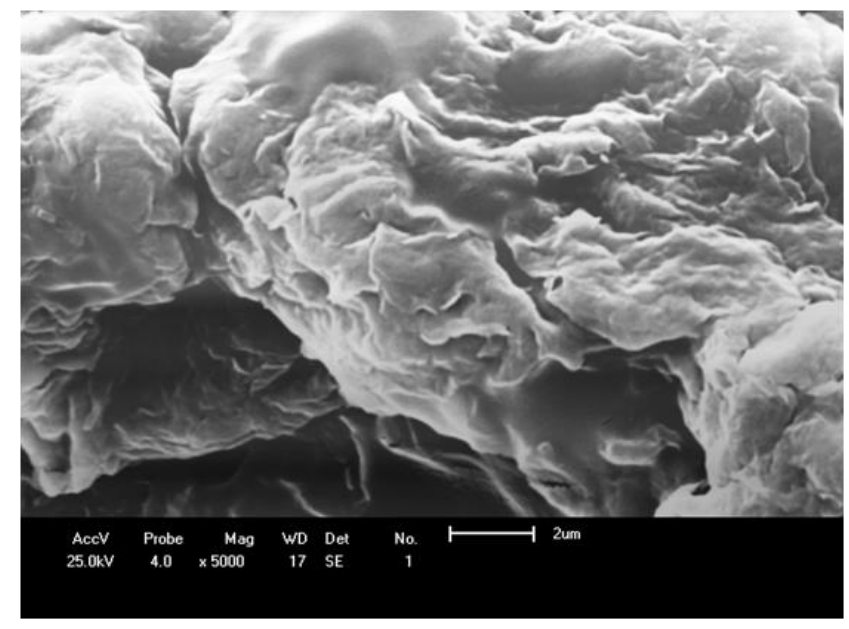

Figura 5: MEV da argila Bentogel - J natural.

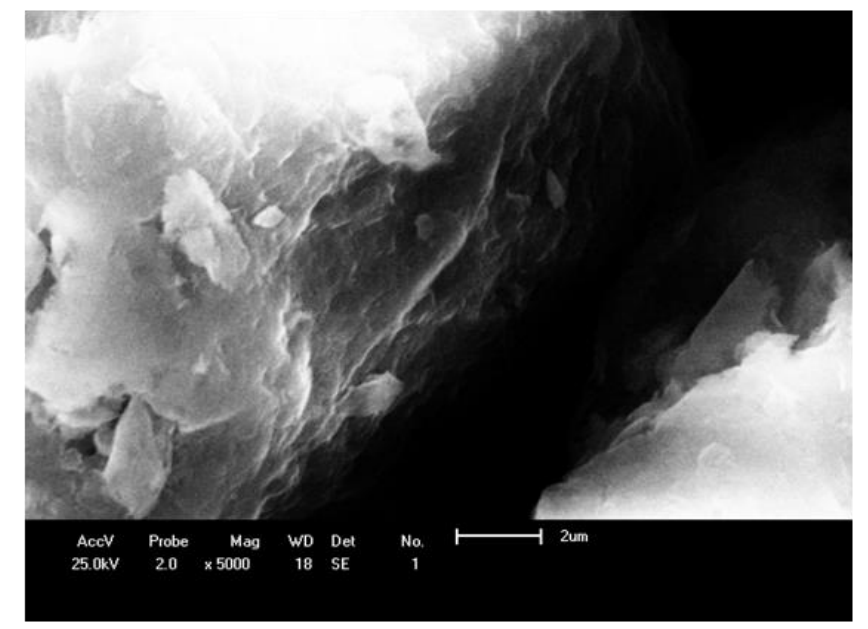

Figura 6: MEV da argila Bentogel - J impregnada.

Observando as micrografias da argila Bentogel - $\mathrm{J}$ natural podendo ser vista através da Figura 5 com ampliação 5000x foi possível verificar que as partículas lamelares encontram-se aglomeradas, não distinguindo claramente a morfologia lamelar. A argila Bentogel - $\mathbf{J}$ natural apresenta um perfil coerente com a estrutura da montmorilonita através da análise de microscopia eletrônica de varredura. Comparando as microscopias da argila Bentogel - J impregnada (Figura 6) com a argila Bentogel - J natural (Figura 5) pode-se perceber que ambas possuem perfil similares. No entanto, a argila Bentogel 
- J impregnada tornou-se provavelmente mais compacta devido ao tratamento térmico promovido pelo processo de impregnação.

\section{Espectroscopia de Energia Dispersiva (EDS)}

Através dos resultados da análise de Espectroscopia de Energia Dispersiva observa-se a composição química qualitativa das argilas Bentogel $-\mathbf{J}$ nas formas natural e impregnada ilustradas nas Figuras 7 e 8, respectivamente.

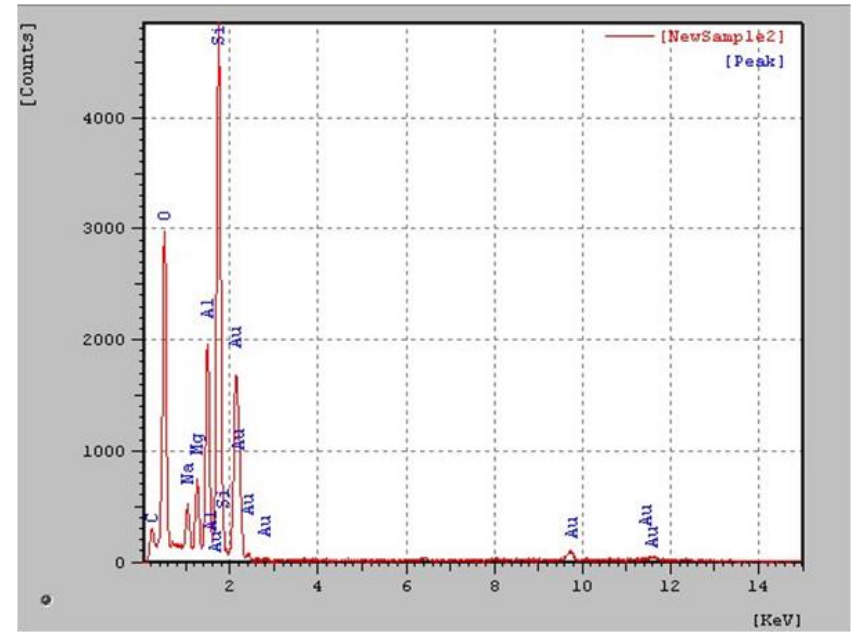

Figura 7: Espectroscopia de energia dispersiva da argila natural.

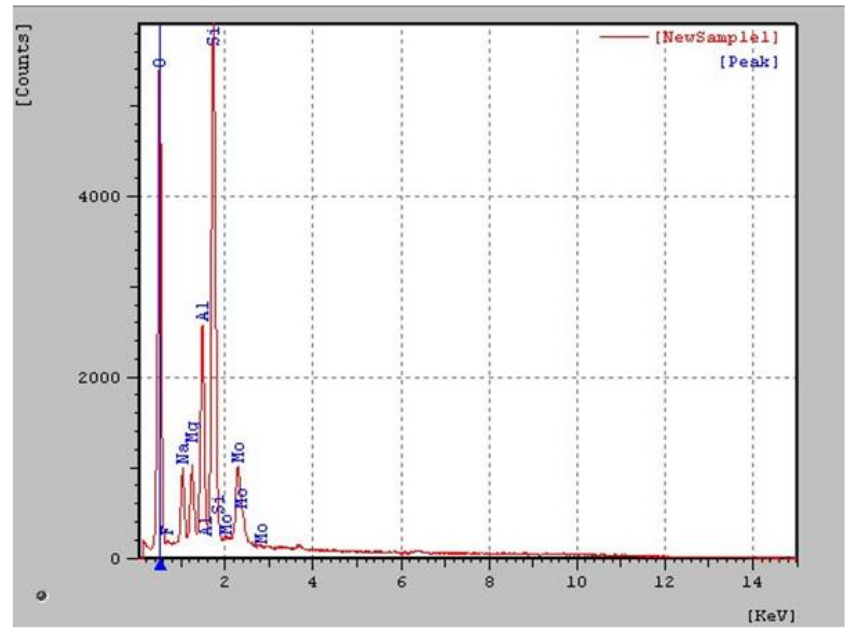

Figura 8: Espectroscopia de energia dispersiva da argila impregnada.

Analisando a argila Bentogel - J natural através da Figura 7 verifica-se que este material possui em sua composição $\mathrm{Si}, \mathrm{Al}, \mathrm{Mg}, \mathrm{Ca}$ e $\mathrm{Na}$, evidenciando uma composição típica da montmorilonita. Comparando os resultados de EDS para as argilas Bentogel - J natural e Bentogel - J impregnada observou-se a presença de molibdênio apresentado na Figura 8 como o metal promissor de ativação. $\mathrm{O}$ ouro $(\mathrm{Au})$ presente nas amostras é proveniente da atomização, com ouro, que as amostras foram submetidas, antes da análise.

\section{Caracterização do óleo e dos biodieseis}


Através da Tabela 1, pode ser observada reduções das viscosidades cinemática e as porcentagens das conversões dos biodieseis (teor de ésteres) obtidos utilizando como catalisador a argila Bentogel - $\mathbf{J}$ nas formas: natural e impregnada.

Tabela 1: Viscosidade cinemática e teor de ésteres.

\begin{tabular}{c|c|c|c}
\hline Amostra & $\begin{array}{c}\text { Viscosidade } \\
\text { Cinemática }\left(\mathrm{mm}^{2} / \mathrm{s}\right)\end{array}$ & $\begin{array}{c}\text { Redução da } \\
\text { viscosidade }(\%)\end{array}$ & Teor de ésteres (\%) \\
\hline Óleo de soja & 34,28 & - & - \\
\hline $\begin{array}{c}\text { Bentogel }-\mathrm{J} \\
\text { Natural }\end{array}$ & 29,74 & 13,24 & - \\
\hline $\begin{array}{c}\text { Bentogel - J } \\
\text { Impregnada }\end{array}$ & 18,17 & 46,99 & 36,72 \\
\hline
\end{tabular}

O produto obtido, utilizando a argila na forma natural como catalisador, apresentou uma pequena redução da sua viscosidade quando comparada a argila que obteve tratamento químico (impregnação). $\mathrm{O}$ processo de impregnação com $\mathrm{o} \mathrm{MoO}_{3}$ na argila potencializou as suas propriedades catalíticas, pois houve um aumento da redução da viscosidade. A redução de viscosidade do biodiesel que foi de 13,24 \% utilizando a argila Bentogel - $\mathbf{J}$ na forma natural como catalisador passando para 46,99 \% utilizando a argila Bentogel - J impregnada como catalisador.

Para identificação da conversão do óleo em teor de ésteres, o biodiesel sintetizado utilizando a argila Bentogel - J impregnada como catalisador foi analisado por cromatografia gasosa, pois este apresentou a maior redução de viscosidade.

Pode-se observar que o tratamento químico na argila através da impregnação na argila foi eficiente ao auxiliar na conversão do óleo vegetal em éster (biodiesel). Esse resultado corrobora com o teor de redução de viscosidade demonstrado anteriormente.

\section{CONCLUSÕES}

A argila Bentogel - $\mathbf{J}$ trata-se de uma argila bentonítica que apresenta a fase montmorilonita predominante.

A argila na forma natural não demonstrou atividade catalítica satisfatória para a obtenção de biodiesel, pois esta quando utilizada como catalisador não obteve redução de viscosidade significativa quando comparada a viscosidade do óleo vegetal.

O tratamento químico (impregnação) sob a argila bentonítica contribuiu para o aumento da redução de viscosidade e da conversão do óleo em éster.

\section{REFERÊNCIAS}


1. SILVA, A. S. Avaliação de catalisadores de NiO e MoO3, suportados em MCM-41, na obtenção de biodiesel de óleo de algodão. Tese (Doutorado em engenharia de processos) - Universidade Federal de Campina Grande, Campina Grande. 2011.

2. SILVA, A. A. Novos catalisadores a base de argilas para a produção de biodiesel. Tese (Doutorado em Engenharia de Processos/UFCG) - Campina Grande-PB (2008).

3. GUERRA, D. L.; SANTOS, M. R. M. C.; AIROLDI, C. Mercury adsorption on natural and organofunctionalized smectites - thermodynamics of cation removal. Journal of Brazilian Chemical Society, v. 20, n. 4, p. 594-603, 2009.

4. RAMOS, L. P.; SILVA, F. R.; MANGRICH, A. S.; CORDEIRO, C. S. Tecnologias de Produção de Biodiesel. Revista Virtual de Química, 2011, v. 3, N 5, pag. 385-405.

5. ZHAO, X. S.; LU, M. G. Q.; MILLAR, G. J., Advances in mesoporous molecular sieve MCM-41. Industrial and Engineering Chemical Research, vol. 35, p. 2075, 1996. 